\title{
Measuring Stress Experienced by University Students
}

\author{
Marco Istasy, Rana Elias, Maria Raheb, and Zack Cernovsky
}

\section{ABSTRACT}

Background: University students often report feeling intense stress, high anxiety, depressive feelings, low self-esteem, suicidal ideation, and substance abuse. This study presents a new questionnaire measure of student stress consisting of $\mathbf{3 0}$ items to investigate the symptoms of stress and potentially protective factors.

Method: A total of 100 Canadian university students (mean age 20.2 years, $\mathrm{SD}=\mathbf{2 . 5}, 33$ males, 67 females) participated in an internet survey. They all completed our 30 item questionnaire dealing with the perceived stress of studying and exams, and with symptoms such as nightmares, depression, feelings of "being better off dead," low self-esteem, and with potentially protective factors such as the extent of positive attitude to professors and pride in or contentment with the social status as a university student.

Results: High proportions of students reported feeling, at least at times, better off dead (52\%). About a half of them felt that most professors do not seem to like them $(56 \%)$ and many reported nightmares about exams $(53 \%)$. Lower perceived levels of student stress were associated with more positive feelings towards the professors $(r=-.37)$ and with more pride in being a university student and the contentment with the related social status $(r=-.25)$. The Cronbach alpha coefficient of internal consistency of our questionnaire was .87 , i.e., satisfactory.

Discussion: The high prevalence of nightmares about exams, feeling of "being better off dead," or of not being liked by the professors is worrisome. Positive relations towards the professors or pride in or contentment about being a university student function as statistically significant but only weak and hence insufficient protective factors.

Conclusions: More than $50 \%$ of students reported nightmares about exams, feeling of "being better off dead," or of not being liked by the professors. Further research is needed to evaluate correlates of student stress to other protective factors than those explored in the present study.

Keywords: Stress, Nightmares, University Students, Depression, Loneliness.

\section{INTRODUCTION}

A recent large scale meta-analytic study on 634, 662 college students published in 2018 indicated that about $10.6 \%$ reported suicidal ideation, plans, or attempts within the previous 12 months and 3\% of them had suicide plans [1]. A recent Mexican study of 4,189 first year university students from 6 Mexican universities found similar proportions: $9.7 \%$ reported suicidal ideation and $3.9 \%$ had a suicide plan within the last 12 months [2]. A recent Chinese study on 6284 college students also reported a similar prevalence for the last 12 months [3].

A systematic review of 17 studies comprising a total of 13,244 medical students in 13 different countries [4] found that prevalence of suicidal ideation ranged from $1.8 \%$ to $53.6 \%$. The risk factors were depression and depressive symptoms, a previous diagnosis of a psychiatric disorder,
Submitted : March 26, 2021

Published : April 16, 2021

ISSN: $2593-8339$

DOI: 10.24018 /ejmed.2021.3.2.787

\section{Istasy}

Departments of Psychology and of Human Biology, University of Toronto, Toronto, Ontario, Canada.

(e-mail: istasym ${ }^{\circledR}$ gmail.com)

R. Elias

Psychiatric Clinic, London, Ontario, Canada.

(e-mail: rana.elias.raheb ${ }^{\circledR}$ gmail.com) M. Raheb

Department of Chemistry, Western University, London, Ontario, Canada.

(e-mail: mraheb@uwo.ca)

Z. Cernovsky*

Department of Psychiatry, Western University, London, Ontario, Canada. (e-mail: drcerovsky ${ }^{\circledR}$ gmail.com)

*Corresponding Author lower socioeconomic status/financial difficulties, having a history of drug use, and feeling neglected by parents [4]. Another review study determined that insomnia and nightmares are associated with elevated prevalence of suicidal thoughts and behaviours and that a thwarted sense of belongingness, socio-cognitive factors, and emotional dysregulation could be important contributing factors [5]. Of course, a very important factor is also the perceived stress of college studies. A very brief screening questionnaires of college stress was developed by Feldt consisting of 11 items [6]: the students' scores on Feldt's questionnaire correlated inversely at a significant level with their scores on a satisfaction with life scale [7].

An extensive questionnaire comprising 48 items to measure stress experienced by college students was developed by Avdija at Indiana State University in 2018. Avdija's scale sampled the perceived practical stress along the following 5 dimensions: Financial stress, Time 
management stress, Social stress, Academic stress, and Family stress [8].

The present study introduces a new 30 item questionnaire that deals with various aspects of perceived emotional stress in university students. The purpose of the questionnaire is to provide an overview for therapeutic counselors of the student's signs of stress such as sleep problems or nightmares, perceived lack of emotional or therapeutic support at the university, loneliness, low self-esteem, lack of pride in being a university student, and the absence of viewing professors as role models for oneself.

\section{MethoD}

The 30 item questionnaire (see the item text in Table 1) offered 5 possible responses: $1=$ very true, $2=$ true, $3=$ neither true nor false, $4=$ false, $5=v e r y$ false. Scoring for 10 items was reversed for calculations of the total score (Items 4, 10, $14,17,19,22,24,28,29$, and 30) so the higher total scores on the 30 items would indicate more intense emotional distress.

University students were recruited for an internet survey from 3 major universities in Ontario, Canada. A total of 100 students provided valid responses to all 30 items. Their mean age was 20.2 years ( $\mathrm{SD}=2.5$, range 18 to 30 ): 33 were males and 67 females.

\section{RESUlTS}

The mean total score was $94.7(\mathrm{SD}=17.3)$ and the Cronbach alpha coefficient of internal consistency was .87 , i.e., satisfactory. The students' scores ranged from 53 to 145 : this indicates that all of them experienced some degree of stress.

In the Table I, the responses very true and true are pooled as "true" and very false and false as "false," to simplify the overview for the readers. In this table, the scoring of positively worded items was left as is: for example, in response to Item 22, slightly more than half of the students $(57 \%)$ agreed that the professors are their role models.

Worrisome are the high proportions of students who report feeling, at times, being better off dead (52\%), or of those feeling that most professors do not seem to like them (56\%), those who report not having any true friends at the university $(50 \%)$, and those who report having nightmares about exams (53\%).

Positive findings are the high proportion of those who report feeling closer to their professors than to other adults outside of their family (81\%) and of those who considers professors as their role models (57\%).

\begin{tabular}{|c|c|c|c|}
\hline Item: & $\begin{array}{l}\% \text { True or } \\
\text { very true }\end{array}$ & $\begin{array}{l}\text { \% Neither } \\
\text { nor }\end{array}$ & $\begin{array}{l}\% \text { False or } \\
\text { very false }\end{array}$ \\
\hline 1. I feel anxious about upcoming exams. & 8 & 19 & 73 \\
\hline 2. It seems that most professors do not like me. & 56 & 33 & 11 \\
\hline 3. The studying for my classes is stressful. & 9 & 20 & 71 \\
\hline 4. I admire my professors. & 21 & 30 & 49 \\
\hline 5. I do not have any true friends at the university. & 50 & 20 & 30 \\
\hline 6. I am a financial burden to my parents. & 33 & 27 & 40 \\
\hline 7. Most professors do not care at all about the wellbeing of us, the students. & 30 & 36 & 34 \\
\hline 8. If I compare myself to other persons, I feel useless. & 26 & 26 & 48 \\
\hline $\begin{array}{l}\text { 9. I have recently at least once drank alcohol to cope with the stress of university } \\
\text { studies. }\end{array}$ & 76 & 8 & 16 \\
\hline 10. I often feel happy to be at the university. & 28 & 34 & 38 \\
\hline 11. My sleep is poor because I am too stressed out by the studies. & 29 & 13 & 58 \\
\hline 12. I have nightmares about exams. & 53 & 13 & 34 \\
\hline 13. I know that a student at our university committed suicide within the last 2 years. & 36 & 3 & 61 \\
\hline 14. I can talk more easily to my fellow students than to other persons of the same age. & 37 & 42 & 21 \\
\hline 15. When I compare myself to others, I feel worthless. & 36 & 23 & 41 \\
\hline 16. I have used non-prescribed drugs recently to cope with the university stress. & 83 & 6 & 11 \\
\hline 17. The university studies are making a better person out of me. & 31 & 29 & 40 \\
\hline 18. Depressive feelings often invade my mind. & 27 & 22 & 51 \\
\hline $\begin{array}{l}\text { 19. It would make me happy if I would learn to speak as elegantly and precisely as my } \\
\text { professors do. }\end{array}$ & 32 & 19 & 49 \\
\hline $\begin{array}{l}\text { 20. At night, I have anxious dreams about not being able to complete (or about not } \\
\text { having completed) the required assignments for my classes. }\end{array}$ & 36 & 15 & 49 \\
\hline 21. At times, I feel I would be better off dead. & 52 & 22 & 26 \\
\hline 22. The professors are my role models. & 57 & 27 & 16 \\
\hline 23. Most students at our university suffer from the great pressure to pass their courses. & 3 & 17 & 80 \\
\hline 24. Being a university student makes me feel proud of myself. & 20 & 23 & 57 \\
\hline 25. Since I started at the university, I feel lonely. & 28 & 22 & 50 \\
\hline 26. The university does not provide effective psychological help for me. & 25 & 32 & 43 \\
\hline 27. When asked how I am, I usually lie that I feel OK. & 22 & 16 & 62 \\
\hline 28. University students are the most intelligent group of young persons in this country. & 48 & 34 & 18 \\
\hline $\begin{array}{l}\text { 29. I feel closer to my professors than to any other adults (except perhaps for some } \\
\text { members of my family). }\end{array}$ & 81 & 13 & 6 \\
\hline 30. The university provides very good help for my struggles. & 49 & 41 & 10 \\
\hline
\end{tabular}


Worrisome are also the high proportions of students who reported using alcohol $(76 \%)$ or non-prescribed drugs (83\%) to cope with the stress of university life. The results on correlations involving the use of alcohol (Item 9) and nonprescribed drugs (Item 16) in this sample of 100 students have already been already reported by Istasy's team in detail elsewhere [9].

\section{A. Correlates of Nightmares about Exams or Uncompleted Assignments}

Item 12 (nightmares about exams, reported by 53\%) and Item 20 (anxious dreams of uncompleted assignments, reported by $36 \%$ ) deserve special attention because such anxiety dreams are considered an important symptom of the Post-Traumatic Stress Disorder (PTSD). When the scores on these 2 items were subtracted from the total stress score, the remaining part of total scores of student's stress was moderately correlated with the reports of nightmares about exams ( $\mathrm{r}=.49, \mathrm{p}<.001,1$-tailed) and also with the reports of anxious dreams about not being able to complete, or about not having completed, the required assignments $(r=56$, $\mathrm{p}<.001,1$-tailed).

The reports of nightmares were highly correlated with reports of anxious dreams about incomplete assignments $(\mathrm{r}=.77, \mathrm{p}<.001,1$-tailed $)$.

\section{B. Correlates of Low Self-Esteem}

As shown in Table 1, 26\% of students reported feeling useless (see Item 8 ) and 36\% reported feeling worthless (see Item 15), when "compared to others." These items are linguistically similar and are highly correlated $(\mathrm{r}=.89)$.

When the scores on these 2 items were subtracted from the total stress score, the remaining part of total score of student's stress was moderately correlated with feelings of being useless $(\mathrm{r}=.52, \mathrm{p}<.001,1$-tailed $)$ and with feeling worthless $(\mathrm{r}=52, \mathrm{p}<.001,1$-tailed). Those feeling useless or worthless felt under higher levels of student stress than students with better self-esteem.

\section{Correlates of Loneliness}

As shown in Table 1, 50\% of the students reported having no true friends at university (Item 5) and 28\% reported feeling lonely since starting university (Item 25). When the scores on these 2 items were subtracted from the total stress score, the remaining part of total score of student's stress was significantly but weakly correlated with having no true friends $(\mathrm{r}=.29, \mathrm{p}=.001,1$-tailed $)$ and moderately correlated with feeling lonely $(\mathrm{r}=.53, \mathrm{p}<.001,1$-tailed $)$. Those more lonely reported higher levels of student stress.

\section{Correlates of Feeling "to Be Better off Dead"}

As already mentioned, about a half of the students (52\%) reported they at times feel they would be better off dead (Item 21). When the score on this item was subtracted from the total stress score, the remaining part of the total score of student's stress was moderately correlated with these reports of feeling to be better off dead $(\mathrm{r}=.55, \mathrm{p}<.001,1$-tailed $)$. Those who reported being better off dead were somewhat more likely to complain that they have no true friends at the university $(\mathrm{r}=.37, \mathrm{p}<.001$, 1-tailed), feel lonely $(\mathrm{r}=.46, \mathrm{p}<.001,1$-tailed $)$, and feel useless $(\mathrm{r}=.47, \mathrm{p}<.001,1$-tailed $)$, or worthless $(\mathrm{r}=.53$, $\mathrm{p}<.001,1$-tailed).

\section{E. Correlates of Depressive Feelings}

The statement "Depressive feelings often invade my mind" (Item 18) was endorsed by $27 \%$ of the students. When the scores on this item was subtracted from the total stress score, the remaining part of the total score of student's stress was highly correlated with the report of depressive feelings $(\mathrm{r}=.60, \mathrm{p}<.001,1$-tailed). Students who reported depressive feelings were more often those who also felt lonely $(\mathrm{r}=.52$, $\mathrm{p}<.001$, 1-tailed $)$ useless $(\mathrm{r}=.58, \mathrm{p}<.001$, 1-tailed $)$, worthless ( $\mathrm{r}=.60, \mathrm{p}<.001,1$-tailed), and more often complained about not having true friends at the university ( $\mathrm{r}=.29, \mathrm{p}=.002$, 1-tailed).

\section{F. Correlates of Viewing Professors as Role Models}

As already mentioned, more than a half of the students (57\%) reported they considered the professors as role models (Item 22). This viewpoint was inversely correlated with the total score for student's stress ( $\mathrm{r}=-.42, \mathrm{p}<.001,1$-tailed) after the score on that particular item was removed from the total. Students who considered their professors as role models were less likely to report high levels of stress.

Considering professors as role models was uncorrelated with the feeling better off dead $(\mathrm{r}=-.030)$, or feeling useless $(\mathrm{r}=-.045)$, or worthless $(\mathrm{r}=-.005)$.

\section{G. Correlates of Good Relationship with Professors}

Items 4, 19, 22, and 29 indicated a good relationship to the professors and the same is also true about Item 2 and Item 7 if the scoring of these two items is reversed. Added together, these 6 items can form a subscale of positive relationship to professors. The Cronbach Alpha coefficient of internal consistency calculated for this subscale is somewhat weak, only .60 , but would still be considered by some experts as acceptable.

All students reported at least some small degree of positive relationship to their professors: the scores on this subscale ranged from 8 to 25 . The sum of scores on these 6 items was only weakly correlated with the overall student stress (a sum of all remaining 24 items): those with more positive view of the professors reported less stress $(\mathrm{r}=-.37, \mathrm{p}<.001,1$-tailed).

Students with a good relationship to professors were less likely to report being better off dead ( $\mathrm{r}=-.23, \mathrm{p}=.011,1$ tailed), to feel lonely ( $\mathrm{r}=-.23, \mathrm{p}=.012,1$-tailed), or to report depressive feelings $(\mathrm{r}=-.20, \mathrm{p}=.023,1$-tailed $)$.

Reports of good relationship to professors were not significantly related ( $p>.05,1$-tailed) to complaints about not having true friends at the university $(\mathrm{r}=-.13)$, and having nightmares about exams $(\mathrm{r}=.-16)$, or anxious dreams about uncompleted assignments $(\mathrm{r}=-.10)$.

\section{H. Correlates of Happiness and Pride of Being a University Student}

Several items describe positive feelings about the university: feeling happy to be at the university (Item 10, endorsed by $28 \%$ ), being able to talk more easily to fellow students than to other persons (Item 14, endorsed by $37 \%$ ), pride of being a university student (Item 24, endorsed by $20 \%$ ), viewing university students as the most intelligent group of young persons in this country (Item 28, endorsed by $48 \%$ ), and noticing that university studies are making a better person out of me (Item 17 , endorsed by $31 \%$ ). 
These 5 items were added together to form a subscale of happiness \& pride. All students reported at least some pride or happiness about being at the university (scores ranged from 5 to 22). The Cronbach's Alpha calculated for this subscale was too low (.54): these 5 items do not form a homogeneous group.

The sum of these 5 items was weakly and in an inverse manner correlated to the total student stress score from which these 5 items (scored in reverse) were subtracted $(\mathrm{r}=-.25$, $\mathrm{p}=.014,1$-tailed): those more happy and proud of their status as university students were reporting somewhat lower levels of stress of being at the university. They less frequently complained about not having true friends at the university $(\mathrm{r}=-.24, \mathrm{p}=.008,1$-tailed). The sum of the 5 items (the "happy and proud" subscale) was not significantly ( $p>.05,1$-tailed) correlated with depressive feelings $\quad(\mathrm{r}=-.14)$, or feeling useless $(\mathrm{r}=-.08)$, or worthless $(\mathrm{r}=-.06)$.

\section{Correlates of Gender and Age}

A large correlation matrix was calculated of all 30 items of the student stress questionnaire to age and gender. The following correlations significant at $\mathrm{p}<.05$ (2-tailed) were found. Older students reported feeling less anxious about upcoming exams $(\mathrm{r}=-.26)$, considered the studying as less stressful than those of younger age $(r=-.21)$, less often viewed themselves as financial burden to their parents $(\mathrm{r}=-.20)$, less often felt useless $(\mathrm{r}=-.21)$ or worthless $(\mathrm{r}=-.21)$, and were less likely to agree that "most students at the university suffer from the great pressure to pass their courses" ( $\mathrm{r}=-.22)$, perhaps because they were more experienced or had better financial resources.

Females somewhat less often reported impaired sleep $(r=-.20)$ due to the stress of studies. Although statistically significant, all these correlations involving age and gender are extremely weak and of negligible value for practical clinical predictions.

Neither age nor gender were significantly correlated with the total score of student stress, and they were also uncorrelated to the group of 6 items indicative of a good relationship to the professors or to the group of 5 items indicative of feeling happy or proud about being a university student.

\section{DISCUSSION}

Our results are consistent with the conclusions of Eisenberg's research team [10] that "Mental health among university students represents an important and growing public health concern for which epidemiological data are needed." All students in the present study reported some degree of university stress. This is not necessarily negative because stress has some activating value: when the stress is not excessive, it motivates the student to maintain attentional focus in the lectures, or when studying from textbooks, or while preparing assignments.

Ibrahim's team [11] undertook an extensive review of literature on the prevalence of depression at universities and concluded that "university students experience rates of depression that are substantially higher than those found in the general population." The impact of depressive ideation on academic performance could be adverse. For example, a study by Saddler and Sacks [12] indicated that depressive ideation is correlated with academic procrastination and also with unconstructive perfectionism. In another study, depression was found to be associated with lower grade point average [13].

High levels of depression, anxiety, and of stress symptoms of university students are a worldwide problem that is now well documented even in countries such as Nigeria [14], Iran [15], Malaysia [16], China [3], [17], [18], and Turkey [19]. The Turkish scientists Bayram and Bilgel [19] emphasized the need for adequate and appropriate support services for this vulnerable but especially valuable group of the general population. Psychological screening of students at the end of the first or second semester with questionnaires such as the one used in the present study is preventively important.

Oliver and Burkham [20] found that the presence of depression in the students did not vary over three points in time during the academic year: this suggests that it is present as a persistent health issue.

The correlational trends found in this study are somewhat difficult to interpret because the causal direction remains unknown. In many cases, the causal influence might be mutual rather than unilateral. For example, as already mentioned, more than a half of the students (57\%) reported they considered the professors as role models and this viewpoint was inversely correlated with the total score for student's stress ( $\mathrm{r}=-.42, \mathrm{p}<.001,1$-tailed). The causal direction that underlies this correlation remains unclear. Students displaying a too overtly negative attitude to the faculty staff in their social interactions with their professors already in their first classes might experience a reciprocal retribution in the form of additional stress or perhaps students who feel excessively stressed by the academic pressure from their professors develop a more negative view of their professors.

It is noteworthy that considering professors as role models, viewing the professors as a positive influence, or also being happy or proud of one's social status as a university student does not completely shield or protect the student from the stress of university studies. Some students decide to view the stress of studies in a positive light and emphasize the positive aspect of the challenging environment, as if following the principles of cognitive behavior therapy.

In the present study, the reports of nightmares about exams correlated significantly (but only weakly) with the students' endorsement of the Item 1 "I feel anxious about upcoming exams." This is not surprising. The stress in the waking life finds its reflection in the content of dreams. Cernovsky's study [21] on Swiss university students found that $50 \%$ of them admitted to having had at least one nightmare in the last 2 years. In $18.2 \%$, these nightmares dealt with examinations. The proportion of students reporting nightmares about exams seems higher in the present study (53\%) than in Cernovsky's Swiss study (18.2\%) conducted at the University of Berne several decades ago, but the reasons for this are unclear. Nightmares are considered an important symptom of PTSD which may linger, in a milder form, over many years. Even Sigmund Freud himself [22] admitted to still having, in his later adult years, recurrent anxious dreams about having to re-take examinations, those he passed many years ago. 


\section{CONCLUSIONS}

Our literature review indicates high levels of emotional stress in university students on a worldwide scale. Our own questionnaire results confirm that this also applies to some major Canadian universities, with occasional suicidal ideation exceeding $50 \%$.

Our article presents a new assessment instrument to help screening students in their first years to detect those most vulnerable. Our correlational analyses indicate that positive relations towards the professors or pride in or contentment about being a university student function as statistically significant but only weak and hence insufficient protective factors. As the next step, psychological research by clinicians in academic settings on strategies for prevention of emotional breakdowns in students is needed.

\section{ACKNOWLEDGMENT}

The authors thank Abe Cernovsky, B. A., for his editorial assistance on this manuscript.

\section{REFERENCES}

[1] Mortier P, Cuijpers P, Kiekens G, et al. The prevalence of suicidal thoughts and behaviours among college students: a meta-analysis. Psychological Medicine. 2018; 48 (4): 554-565. doi: 10.1017/S0033291717002215.

[2] Benjet C, Gutiérrez-García RA, Abrego-Ramírez A, et al. Psychopathology and self-harm among incoming first-year students in six Mexican universities. Salud Publica de Mexico. 2019; 61 (1): 1626. doi: 10.21149/9158.

[3] Wang M, Kou C, Bai W, et al. Prevalence and correlates of suicidal ideation among college students: A mental health survey in Jilin Province, China. Journal of Affective Disorders. 2019; 246: 166-173. doi: 10.1016/j.jad.2018.12.055.

[4] Coentre R and Góis C. Suicidal ideation in medical students: recent insights. Advances in Medical Education and Practice. 2018; 9: 873880. doi: 10.2147/AMEP.S162626.

[5] Russell K, Allan S, Beattie L, et al. Sleep problem, suicide and selfharm in university students: A systematic review. Sleep Medicine Reviews. 2019; 44: 58-69. doi: 10.1016/j.smrv.2018.12.008.

[6] Feldt RC. Development of a brief measure of college stress: the college student stress scale. Psychological Reports. 2008; 102 (3): 855-60.

[7] Weinstein L, and Laverghetta A. College student stress and satisfaction with life. College Student Journal. 2009; 43 (4): 11611162 .

[8] Avdija AS. College Stress: Testing the Unidimensionality of a Standardized Stress Measuring Inventory Designed to Assess Stress among College Students. Children and Teenagers. 2018; 1 (2): 68-83. doi: $10.22158 /$ ct.v1n2p68.

[9] Istasy M, Elias R, Raheb M, Cernovsky Z. Substance Abuse and Stress Levels in Canadian University Students. Archives of Psychiatry and Behavioral Sciences. 2019; 2 (2): 1-6.

[10] Eisenberg D, Gollust SE, Golberstein E, Hefner JL. Prevalence and Correlates of Depression, Anxiety, and Suicidality Among University Students. American Journal of Orthopsychiatry. 2007; 77 (4): 534542. doi.org/10.1037/0002-9432.77.4.534.

[11] Ibrahim AK, Kelly SJ, Adams CE, Glazebrook C. A systematic review of studies of depression prevalence in university students. Journal of

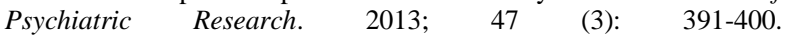
doi.org/10.1016/j.jpsychires.2012.11.015.

[12] Saddler CD \& Sacks LA. Multidimensional perfectionism and academic procrastination: Relationships with depression in university students. Psychological Reports. 1993; 73 (3, Pt. 1): 863-871. http://dx.doi.org/10.2466/pr0.1993.73.3.863.

[13] Hysenbegasi A, Hass SL, Rowland CR. The Impact of Depression on the Academic Productivity of University Students. The Journal of Mental Health Policy and Economics. 2005; 8: 145-151.

[14] Adewuya AO, Ola BA, Aloba OO, Mapayi BM, Oginni OO. Depression amongst Nigerian university students: Prevalence and sociodemographic correlates. Social Psychiatry and Psychiatric Epidemiology. 2006; 41 (8): 674-678.
[15] Sarokhani D, Delpisheh A, Veisani Y, Sarokhani MT, Manesh RE, Sayehmiri K. Prevalence of Depression among University Students: A Systematic Review and Meta-Analysis Study. Depression Research and Treatment. 2013; Volume 2013. Article ID 373857, 7 pages. http://dx.doi.org/10.1155/2013/373857.

[16] Shamsuddin K, Fadzil F, Ismail WSW, Shah SA, Omar K, Muhammad NA, Jaffar A, Ismail A, Mahadevan R. Correlates of depression, anxiety and stress among Malaysian university students. Asian Journal $\begin{array}{lllll}\text { of } & \text { Psychiatry. } & 2013 ; & 6 & \text { (4): }\end{array}$ doi.org/10.1016/j.ajp.2013.01.014.

[17] Chen L, Wang L, Qiu XH, Yang XX, Qiao ZX, Yang YJ, Yuan Liang Y. Depression among Chinese University Students: Prevalence and Socio-Demographic Correlates. PLOS ONE. Published: March 13, 2013. doi.org/10.1371/journal.pone.0058379.

[18] Chen L, Wang L, Qiu XH, Yang XX, Qiao ZX, et al. Correction: Depression among Chinese University Students: Prevalence and Socio-Demographic Correlates. PLOS ONE. Published November 6, 2013; 8 (11): 10.1371/annotation/e6648eb3-37d6-44d7-8052979af14fa921. doi.org/10.1371/annotation/e6648eb3-37d6-44d78052-979af14fa921.

[19] Bayram N \& Bilgel N. The prevalence and socio-demographic correlations of depression, anxiety and stress among a group of university students. Social Psychiatry and Psychiatric Epidemiology. 2008; 43 (8): 667-672. doi.org/10.1007/s00127-008-0345-x.

[20] Oliver JM \& Burkham R. Depression in university students: Duration, relation to calendar time, prevalence, and demographic correlates. Journal of Abnormal Psychology. 1979; 88 (6): 667-670. http://dx.doi.org/10.1037/0021-843X.88.6.667.

[21] Cernovsky ZZ. Reported nightmare frequency in Swiss university students. Perceptual and Motor Skills. 1983; 57: 1169-1170.

[22] Freud S. The Interpretation of Dreams. Translated by J Strachey. Harmondsworth, UK: Penguin Books, 1976. Originally published in German in 1900 as Die Traumdeutung.

Marco Istasy is a fourth-year neuroscience student at the University of Toronto pursuing an Honours Bachelor of Science.

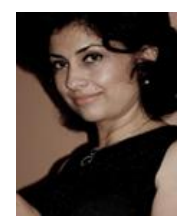

Rana Elias graduated from the medical school in Syria and settled in Canada in 1999. Dr. Elias is presently the manager of methadone/suboxone clinic in London, Ontario, Canada. Her research interest and publications deal with herbal anti-inflammatory medications and also with correlates of stress in university students.

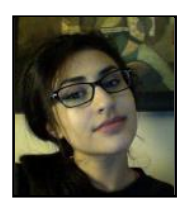

Maria Raheb is currently in her final year of undergraduate studies at the University of Western Ontario (also known as Western University) in London, Ontario, Canada, pursuing an Honours Specialization in Applied Mathematics and Major in Chemistry. Her interests are in simulating dynamical systems and drug design.

Zack Z. Cernovsky is the professor of psychiatry in the medical school of Western University, Canada. Dr. Cernovsky has published close to 200 scientific articles in the field of psychiatry and medical psychology, and also chapters in university textbooks. 